Pediat. Res. 1: 59-65 (1967)

Growth

intelligence tests

precocious puberty

\title{
Elevated Verbal IQ and Idiopathic Precocious Sexual Maturation
}

\author{
J. Money and T. Meredith \\ Department of Psychiatry and Behavioral Sciences and \\ Department of Pediatrics, The Johns Hopkins University and Hospital, \\ Baltimore, Maryland 21205, USA
}

Extract

Eight boys and 27 girls with idiopathic sexual precocity were examined for IQ, with results as follows:

\begin{tabular}{|c|c|c|c|c|}
\hline $\begin{array}{l}\text { Wechsler and } \\
\text { Binet tests }\end{array}$ & Stanford- & $N$ & $\mathrm{M}$ & $\mathrm{SD}$ \\
\hline All cases & . & 35 & 108.4 & 22.7 \\
\hline Boys only &.. & 8 & 112.8 & 21.5 \\
\hline Girls only. & . . . . & 27 & 107.1 & 23.2 \\
\hline
\end{tabular}

\begin{tabular}{lrrrl}
\hline Wechsler test only & $\mathrm{N}$ & $\mathrm{M}$ & $\mathrm{SD}$ \\
\hline Boys, verbal IQ . . . . & \multicolumn{1}{c}{4} & 134.3 & 21.5 \\
Boys, performance IQ & $\cdot$ & 4 & 113.0 & 11.6 \\
Girls, verbal IQ · . . . & 21 & 112.8 & 22.2 \\
Girls, performance IQ &. & 21 & 102.0 & 14.7 \\
\hline
\end{tabular}

On Wechsler subtests, special quotients were obtained for Verbal Comprehension (Information + Comprehension + Similarities + Vocabulary), Perceptual Organization (Block Design + Object Assembly) and Arithmetic, with results as follows:

\begin{tabular}{llrl}
\hline Wechsler subtest quotients & N & M & SD \\
\hline Verbal comprehension . & 23 & 12.7 & 3.6 \\
Perceptual organization . & 23 & 9.5 & 2.2 \\
Arithmetic . . . . . . . & 25 & 11.4 & 4.8 \\
\hline
\end{tabular}

The Mean Verbal-Performance IQ discrepancy was most marked in those with high IQs:

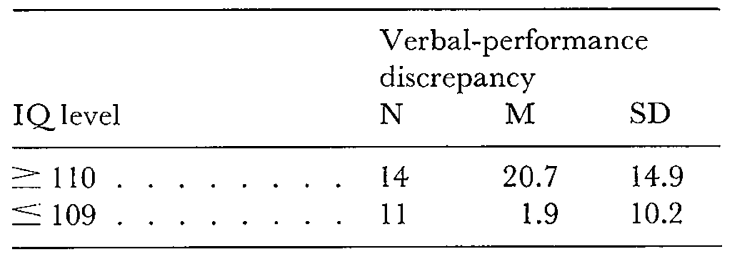

The Verbal-Performance IQ discrepancy appeared to be independent of age and duration of precocity. However, children under five (and therefore tested with the Stanford-Binet which does not yield separate $\mathrm{V}-\mathrm{P}$ scores) had a lower mean $\mathrm{IQ}(\mathrm{M}=101$; $\mathrm{SD}=28.5)$ than the older childrenwhich suggests that high verbal ability was not yet in evidence.

In three cases of serial testing over a twelve year span, the IQ remained Superior or Very Superior, except that the final IQ in one patient, at age 20, had fallen from 133 at age $81 / 2$ and 123 at age $153 / 4$ to 115 . 
The overweighting with six IQs above 130 was accounted for by six local children, three of whom were siblings.

\section{Speculation}

One may conjecture that idiopathic sexual precocity confers on a child a possible advantage in social exposure and participation with older agemates, which in turn confers an advantage in intellectual growth, particularly in the growth of verbal intelligence. This advantage shows up in a Verbal IQ superior to Performance IQ which, once established, is maintained into adulthood. It is not like the temporary advantage of statural superiority that is terminated by premature epiphyseal closure. Whether or not the syndrome of idiopathic precocious puberty tends to induce high IQ, Verbal or Performance, is a question that cannot be properly answered from the present findings. Quite possibly it does. Yet, if such be the case for some children, then it is equally the case that it is not so for others. There are some on whom no intellectual advantage is conferred, for low IQ and mental retardation also concur with precocious puberty.

\section{Introduction}

Sexual precocity may be due to any one of a variety of causes including adrenal hyperplasia, gonadotropin secreting tumors, sex hormone secreting tumors of the testis, ovary or adrenal, brain lesions affecting neurohumoral activation of the pituitary, and idiopathic overactivity of the pituitary. Premature but otherwise nonpathologic release of pituitary gonadotropin is the responsible factor for the activation of the gonads and hence of early hormonal puberty in the examples of sexual precocity labeled idiopathic or constitutional. This type of precocity is believed to account for up to $75 \%$ of the reported cases in girls and $40 \%$ in boys. Idiopathic sexual precocity is more common in girls than boys. Though exact epidemiologic statistics are lacking, the sex ratio has been estimated at $4: 1$.

Sexual precocity of the idiopathic type is manifested somatically by advanced bone age, and nearly always by advanced statural growth velocity during infancy and early childhood, though not later. All the secondary sex characteristics appear prematurely. Pubertal changes may begin as early as the first year of life. After the age of nine years, puberty in girls is usually not considered precocious. The corresponding age for boys is eleven years. Because epiphyseal closure occurs earlier than usual it almost invariably results in short ultimate stature, though there are occasional exceptions. To date, no pharmacologic agents have succeeded in restoring the schedule of development of an affected individual to normal. The progestinic hormone, medroxyprogesterone acetate (Provera ${ }^{\circledR}-U$ pjohn) has been used to retard breast growth and menstruation in girls, but in some cases difficulty is ultimately encountered in establishing normal menstrual cycles.

Somatic overgrowth and early sexual development cause social problems not usually encountered in child- hood; however, with intelligent handling of social developmental issues raised by somatic precocity many children achieve satisfactory emotional development and adjustment $[1,2,4,6]$.

\section{Purpose}

Little is known regarding IQ in subjects with idiopathic sexual precocity. The purpose of this paper is 1. to determine whether in the sample studied accelerated somatic growth was accompanied by elevated mean IQ levels; 2 . to compare verbal and nonverbal intelligence; 3 . to compare, when data were available, the sequence of IQs obtained in longitudinal testing and to compare subgroups of individuals according to age of pubertal onset and time elapsed before testing; and 4. to relate the results obtained from this population sample to those observed in a similar study of children with the adrenogenital syndrome.

\section{Sample Selection}

The sample was drawn from a population of 48 cases seen in the pediatric endocrine clinic between 1952 and mid 1964, plus one supernumerary case from 1965. The 49 cases satisfied the following criteria: 1. a diagnosis of idiopathic sexual precocity with etiological exclusion of tumors, GNS lesions, extraneous or ingested estrogens and syndromes of multiple congenital anomalies; 2. onset of puberty before eight years of age and advanced development by age nine years as demonstrated by full adolescent physique in girls, and appearance of menses (except for five girls whose menses were intentionally delayed by the investigative administration of the progestinic hormone, Provera ${ }^{\circledR}$ ). In boys there was 
usually indirect evidence of ejaculation and in a few instances direct evidence of spermatogenesis in testicular biopsy material.

Of the 49 identified cases, 45 were seen in psychologic consultation and 35 of these, sampled without known bias, were given an intelligence test. This report concerns results obtained from these 35 children.

The age range of the patients when first seen in the psychohormonal research unit varied from 25 months to ten years. When more than one IQ was available for a patient, the one chosen for the present study was that obtained at the age nearest to the time when the patient showed maximum disparity between chronological age and total sexual maturity. The youngest patient tested was twenty-five months of age. Ten scores were obtained from patients under the the age of five years and 24 from patients between five and twelve years of age. One score came from a patient, the only one located in attempts to recall formerly untested patients, who was 18 years old at the time of testing.

Two sisters and a brother from a single sibship were included in the patient sample; a third sister was sexually normal.

\section{Procedure}

Intelligence test data, accumulated over a 13-yearperiod, 1952-1965, were taken from the patients' records. Three different intelligence tests were used, as

Table I. IQ means and standard deviations in idiopathic sexual precocity $(\mathrm{N}=35)$

\begin{tabular}{|c|c|c|c|c|}
\hline Test & Sample & $\mathrm{N}$ & Mean & $\mathrm{SD}$ \\
\hline Wechsler Full Scale & $o+q$ & 25 & 111.28 & 19.80 \\
\hline Wechsler Verbal . . & $\delta+q$ & 25 & 116.24 & 23.50 \\
\hline Wechsler Performance & $\hat{\sigma}+q$ & 25 & 103.80 & 14.63 \\
\hline Stanford-Binet . . . & $5+q$ & 10 & 101.20 & 28.46 \\
\hline \multicolumn{5}{|l|}{ Stanford-Binet and } \\
\hline Wechsler. . . & $\hat{o}+q$ & 35 & 108.40 & 22.67 \\
\hline Wechsler Full Scale & q & 21 & 108.38 & 19.34 \\
\hline Wechsler Verbal. . . & q & 21 & 112.81 & 22.17 \\
\hline Wechsler Performance & \% & 21 & 102.05 & 14.72 \\
\hline Stanford-Binet . . . & 운 & 6 & 102.66 & 35.81 \\
\hline \multicolumn{5}{|l|}{ Stanford-Binet and } \\
\hline Wechsler. . . . & 우 & 27 & 107.11 & 23.24 \\
\hline Wechsler Full Scale & $\widehat{0}$ & 4 & 126.50 & 17.06 \\
\hline Wechsler Verbal. & 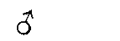 & 4 & 134.25 & 21.47 \\
\hline Wechsler Performance & 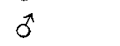 & 4 & 113.00 & 11.60 \\
\hline Stanford-Binet . . . & $\hat{0}$ & 4 & 99.00 & 16.79 \\
\hline \multicolumn{5}{|l|}{ Stanford-Binet and } \\
\hline Wechsler. . . . & $\hat{\sigma}$ & 8 & 112.75 & 21.48 \\
\hline
\end{tabular}

the 35 patients ranged in age from 2 to 18 years. The following tests were given: Revised Stanford-Binet to 10 patients under 5 years of age; the Wechsler Intelligence Scale for Children (WISC) to 24 patients between 5 and 12 years of age; and the Wechsler Adult Intelligence Scale (WAIS) to 1 patient 18 years of age.

\section{Findings}

\section{A. IQ Means and Distribution}

A summary of findings is presented in table I. A mean IQ score of 100 and a SD of 15 is expected on the Wechsler Test from a randomly sampled population. Our sample of 35 patients produced the following figures: $\mathrm{M}=108.4 ; \mathrm{SD}=22.7 ; \mathrm{SE}_{\mathrm{M}}= \pm 3.89$. These figures obscure, however, the high superiority of the small male sample and the general superiority of all

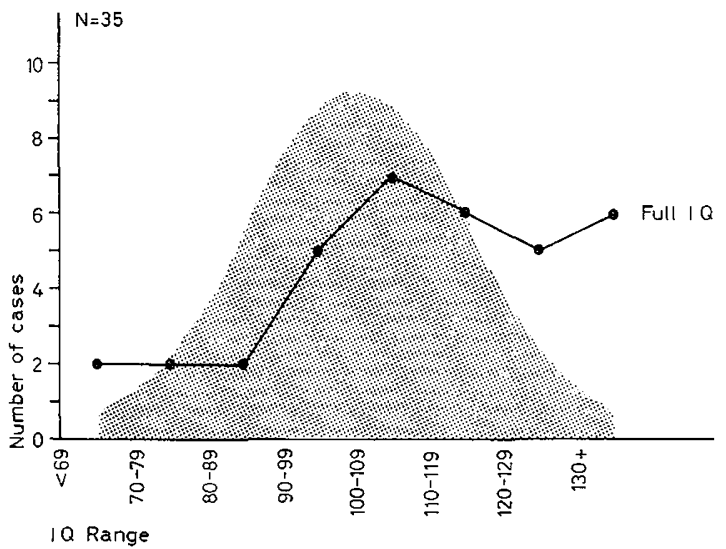

Fig.1. Distribution in idiopathic sexual precocity of expected (shaded area) and observed Full IQ $(\mathrm{N}=35)$.

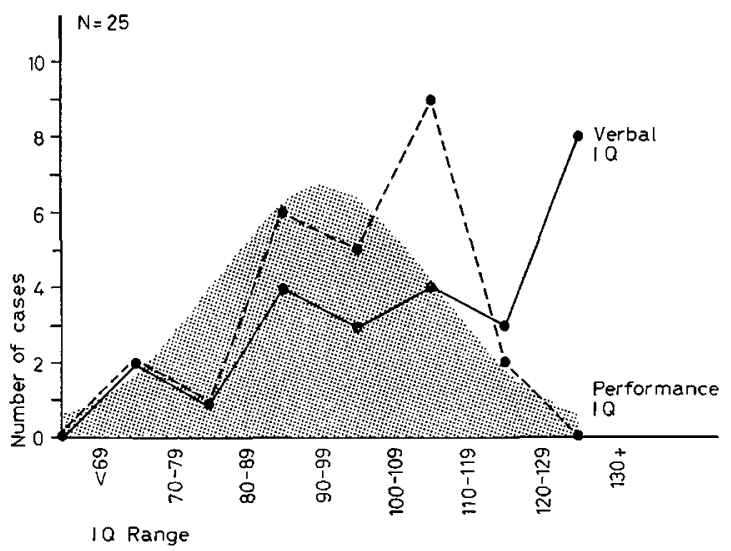

Fig.2. IQ: Verbal, Performance and expected (shaded area) distribution in idiopathic sexual precocity $(\mathrm{N}=$ 25). 
Table II. Expected and observed frequency incidence at each IQ level $(\mathrm{N}=35)$

\begin{tabular}{lllllll}
\hline Levels of IQ & $\begin{array}{l}\text { Expected } \\
\text { percent }\end{array}$ & $\begin{array}{l}\text { Expected } \\
\text { number }\end{array}$ & $\begin{array}{l}\text { Observed } \\
\text { per cent }\end{array}$ & $\begin{array}{l}\text { Observed } \\
\text { number }\end{array}$ & $\begin{array}{l}\text { Cumulative } \\
\text { expected } \\
\text { per cent }\end{array}$ & $\begin{array}{l}\text { Gumulative } \\
\text { observed } \\
\text { per cent }\end{array}$ \\
\hline$\leq 69$ & 2.2 & 0.8 & 5.7 & 2 & 100.0 & 99.9 \\
$70-79$ & 6.7 & 2.3 & 5.7 & 2 & 97.8 & 94.3 \\
$80-89$ & 16.1 & 5.6 & 5.7 & 2 & 91.1 & 88.6 \\
$90-99$ & 25.0 & 8.8 & 14.3 & 5 & 75.0 & 82.8 \\
$100-109$ & 25.0 & 8.8 & 20.0 & 7 & 50.0 & 68.5 \\
$110-119$ & 16.1 & 5.6 & 17.1 & 6 & 25.0 & 48.5 \\
$120-129$ & 6.7 & 2.3 & 14.3 & 5 & 8.9 & 31.4 \\
$130+$ & 2.2 & 0.8 & 17.1 & 6 & 2.2 & 17.1 \\
\hline
\end{tabular}

Table III. Wechsler subtest means and standard deviations

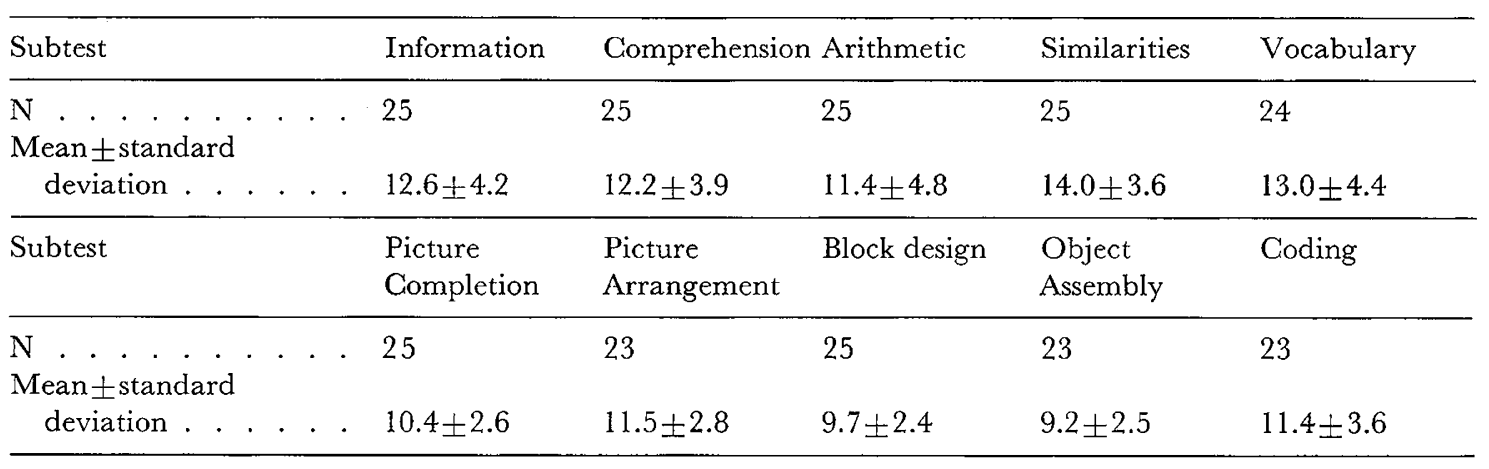

who could negotiate the Wechsler tests. There was an unexpectedly high proportion of Superior and Very Superior scores in the sample (table II). The skewed nature of the distribution can be appreciated also by inspection of figs. 1 and 2. Another feature is the generally higher level of Verbal over Performance IQ (see below).

\section{B. Sex Difference}

It commonly is claimed that the mean IQ of females in the general population is slightly greater than 100 . Since idiopathic sexual precocity is predominantly found in females, and since the sample population consisted mainly of 27 girls, means were calculated for the female and male sections of the sample separately (table I). The 8 boys, it will be seen, are clearly superior, but the sample is too small to permit a firm conclusion. Some girls in the sample also obtained high scores, including the two sisters of the boy in the one instance of plural familial incidence.

C. Wechsler Subtest Scores

The mean and standard deviation of each of the subtest scores of the Wechsler tests were calculated and are presented in table III. Only one of the five Verbal subtest means, Arithmetic (Digit Span was generally omitted), is as low as or lower than the highest of the Performance subtest means. It is markedly lower than the other four in the Verbal category. It is not one of the Verbal scores used in the calculation of a Verbal Comprehension score according to Cohen (see below).

\section{Gohen's Factors}

In 23 of the 25 cases in which the Wechsler test was administered the data were sufficient to calculate two Cohen's factors, Verbal Comprehension and Perceptual Organization. Verbal Comprehension is the average of the scaled scores of four Wechsler subtests: Information, Comprehension, Similarities, and Vocabulary. Perceptual Organization is the average score of the two subtests Block Design and Object Assembly. The mean for Verbal Comprehension was 12.7 ( $\mathrm{SD}=$ 3.6 ); the Perceptual Organization mean was 9.5 (SD $=2.2$ ). Subjected to a t-test, this difference is significant at beyond the 0.001 level $(t=5.54)$. Cohen's third factor, Freedom from Distractibility (the aver- 
Table IV. Age comparisons, S-B and Wechsler scores

\begin{tabular}{|c|c|c|c|c|c|c|c|c|c|c|c|c|}
\hline \multirow{3}{*}{$\begin{array}{l}\text { Age at } \\
\text { onset of } \\
\text { precocity } \\
\text { neonatal } \\
\text { to } 4 \text { years }\end{array}$} & \multirow{2}{*}{$\begin{array}{l}\text { Age } \\
\text { tested } \\
\text { (years) }\end{array}$} & \multirow[b]{2}{*}{ N. } & \multicolumn{3}{|c|}{ Full IQ } & \multicolumn{3}{|c|}{$\begin{array}{l}\text { Perceptual } \\
\text { organization }\end{array}$} & \multicolumn{3}{|c|}{$\begin{array}{l}\text { Verbal } \\
\text { comprehension }\end{array}$} & \multirow[b]{2}{*}{ Test } \\
\hline & & & M. & Med. & Range & M. & $\mathrm{Me}$ & . Range & M. & Med & 1. Range & \\
\hline & & 10 & 101.2 & 103 & $\leq 50-160$ & & -* & & & -* & & Binet \\
\hline $6 \mathrm{mo}$ to & 5 to 6 & & & & & & & & & & & \\
\hline $41 / 2$ years & & 3 & 124 & 125 & $102-145$ & 10 & 9 & $8.5-12.5$ & 15.7 & 16 & $12-19$ & Wechsler \\
\hline $\begin{array}{l}4 \text { months } \\
\text { to } 4 \text { years }\end{array}$ & 7 to 10 & 4 & 119.8 & 118 & $110-133$ & 9.6 & 9.5 & $8.5-11$ & 14.2 & 14.3 & $11.8-16.8$ & Wechsler \\
\hline $\begin{array}{l}5 \text { to } 6 \\
\text { years }\end{array}$ & $\begin{array}{l}6^{1 / 3} \text { to } 71 / 2 \\
(6 \text { cases }) \\
8 \text { to } 81 / 2 \\
(2 \text { cases })\end{array}$ & 8 & 112 & 114 & $83-133$ & 10 & 9.5 & $6-13.5$ & 13.3 & 15 & $7-8-17.5$ & Wechsler \\
\hline $\begin{array}{l}61 / 2 \text { to } 81 / 2 \\
\text { years }\end{array}$ & $\begin{array}{l}81 / 2 \text { to } 12 \\
\text { (9 cases) } \\
18 \\
(1 \text { case) }\end{array}$ & 10 & 103.5 & 105.5 & $68-137$ & 8.8 & 9.5 & $5.5-11$ & 14.4 & 10.9 & $5-8-18.2$ & Wechsler \\
\hline
\end{tabular}

* Not calculable from the Stanford-Binet test

age of Arithmetic + Digit Span) could not be evaluated as too many of the tests in years past had been done with the optional subtest, Digit Span, omitted.

E. Verbal and Performance IQs (fig. 2)

For the combined sample of boys and girls (table I), the difference between the Wechsler Verbal mean score $(\mathrm{M}=116.24, \mathrm{SD}=23.5)$ and the Performance mean score $(\mathrm{M}=103.8, \mathrm{SD}=14.63)$ is statistically significant $(t=3.92, p<0.001)$. After subdividing the sample into patients with Wechsler IQ $\geq 110(\mathrm{~N}=14)$ those with Wechsler $I Q \leq 109(N=11)$, the value of the Verbal minus Performance subscores for the individuals was averaged in each subgroup. The average Verbal minus Performance difference for the group with IQ $\geq 110$ was 20.71 (SD = 14.86); the comparable average for the subsample with $\mathrm{I} Q \leq 109$ was 1.9 $(\mathrm{SD}=10.22)$. The possible relationship of Verbal IQ superiority to age is examined in the section that follows.

F. Comparative Study of Age Differences

Table IV shows the sample subdivided into five subgroups on the basis of age of onset of precocity and the age at which tested. This table shows that the superiority of Verbal Comprehension over Perceptual Organization is consistent throughout the age range, except that the discrepancy could not be measured under five years of age. At this age, the lower age limit for the Wechsler test, the Stanford-Binet test must be used. The Verbal Comprehension mean remained remarkably constant over the four age groups represented, as did also the Perceptual Organization mean; however, the range in both instances showed wide diversity of individual difference.

These individual differences appear also in the wide range of scores, from below 50 to 160 , for the Full IQ.

Table $V$. Serial testing, three cases

\begin{tabular}{|c|c|c|c|}
\hline Age & $\begin{array}{l}\text { IQ } \\
\text { Full }\end{array}$ & Verbal & Performance \\
\hline \multicolumn{4}{|c|}{ R.E. No.53-48-28; male } \\
\hline $510 / 12$ & . . 145 & 153 & 128 \\
\hline $100 / 12$. & . . 133 & 156 & 101 \\
\hline $116 / 12$. & . . 137 & 154 & 111 \\
\hline $1311 / 12$ & 141 & 148 & 125 \\
\hline $188 / 12$. & . . 136 & 140 & 127 \\
\hline \multicolumn{4}{|c|}{ D.W. No.88-83-20; female } \\
\hline $86 / 12$. & . . 133 & 137 & 124 \\
\hline $159 / 12$ & 123 & 133 & 107 \\
\hline $203 / 12$ & 115 & 118 & 110 \\
\hline \multicolumn{4}{|c|}{ L.W. No.69-48-49; female } \\
\hline $611 / 12$ & . . 133 & 144 & 115 \\
\hline $1311 / 12$ & 141 & 152 & 122 \\
\hline $1710 / 12$ & 133 & 141 & 119 \\
\hline
\end{tabular}


The small size of the groups and the large individual variability prohibit facile generalizations. However, one may note a tendency for the IQ to be lower when measured in cases of early onset of precocity prior to the age of five, using the Stanford-Binet. The highest IQ in this group of ten children was 116 , except for one child with an IQ of 160. This IQ of 160, obtained at the age of $4 \frac{1}{2}$, is in marked contrast to the IQ of 109 obtained for the same child on the same test at the age of 3 years. The highest full IQ means were obtained for the groups tested when the children were between 5 and $81 / 2$ years of age. After that, the tendency for IQ elevation may have decreased, with a corresponding slight diminution in the special Verbal Comprehension score.

\section{G. Longitudinal Age Comparisons}

Three or more serial test results were available for three patients (table V). In each case they span a twelve year period. In all three cases and on all testings, the disparity in favor of Verbal IQremains in evidence. The IQ itself also remains rather surprisingly constant, and does not exhibit a tendency toward sudden, early blooming followed by progressive early decline. The single exception is the fall in Verbal IQ in the patient, D.W., at the age of 20 . Only continued study will disclose whether this single instance of a diminished score represents an early aging effect, or whether it is fortuitous. It may have been a side-effect of test anxiety which had been a chronic severe problem in this girl's college history.

\section{H. Residential Locality}

It might be suggested that our sample is biased. There is no known evidence to suggest that idiopathic sexual precocity has a higher incidence in an upper socioeconomic group than in a lower one. The present sample represents all degrees of wealth, with no obvious overloading of any one socioeconomic group. Nor is there any obvious preponderance by race, religion, parental educational status, or residential distance from the hospital. This latter criterion is important, since it may be argued that patients referred to The Johns Hopkins Hospital from distant places are drawn from a select group in social and economic background and intellectual achievement. Evidence contrary to this source of bias is found by examining the residence of the six children with IQs over 130. Three of these patients were siblings from a family having lived in Baltimore for three generations; one was from another family with long residence in Baltimore; a fifth moved to this city from Europe, because of his precocity, when he was four years of age; and the sixth was referred from a nearby city without a major medical center. There is thus no evidence of geographic bias.

\section{Discussion}

A continuous hormonal effect on the nervous system contemporaneous with hormonal induction of precocious sexual development might be postulated to explain the elevated mean IQ of the sample. This hypothesis cannot be directly tested, because no method has yet been found of arresting precocious sexual development. It has not been possible to compare a hormonally advanced group of patients with a group which started to advance but was then brought under control. However, the comparison of groups according to age of onset of precocity indicates that the duration of precocious somatic growth in and of itself does not control precocious intellectual development. Moreover, in the adrenogenital syndrome, which also induces precocious somatic maturation (though always of a virilizing type) it did prove possible to study the effect of arresting precocious development [5]. This same conclusion was reached. As a group, adrenogenital patients exhibit an increase in IQ over that expected from a random sample; $60 \%$ of the sample instead of the expected $25 \%$ obtained an IQ above 109 . The group under study was divided among those who had advanced through early puberty and beyond, and those whose precocious development had been arrested early in life by therapy with cortisone. Both samples showed the same proportional tendency toward IQ elevation.

The contrasting effect of retarded somatic growth can be examined in pituitary and constitutional dwarfism. Affected individuals commonly show a slowed pattern of physical maturation and delayed or defective sexual development if they are not treated with replacement therapy. PollitT and Money [7] showed that as a group hypopituitary dwarfs have a normal range of IQ. An enlarged study incorporating this same sample has confirmed this finding, and extended it to include a study of constitutional dwarfism [3]. A retarded schedule of hormonal, somatic and sexual maturation is not, de facto, associated with a lag in the development of intellectual capacity. Apparently, the hormonal factors governing somatic development are not responsible for a parallel course of mental development.

It is well known that different body systems exhibit different rates and durations of growth. In the syndrome of idiopathic sexual precocity, not all schedules of development seem to be affected in the same way. The bones develop at an accelerated rate, but the epiphyses close early, stunting the final height. The teeth maintain a growth rate fairly compatible with chronological age. The hair and the nails grow continuously, as in nonprecocious individuals. Mental development appears to follow its own course, also compatible with chronological age. Elevation of IQ, when 
in evidence, is present at an early age and continues throughout the developmental period and, no doubt, beyond. If the factors in the etiology of the accelerated somatic maturation, whatever their nature, should be responsible also for organizing the nervous system into a more efficient pattern with respect to intelligence, they probably come into play early, so that when a patient is seen for the physical signs of the syndrome, the mental advantage has already been established. These responsible factors could be genetic or metabolic. They could have their effect during a critical period, in prenatal or neonatal life.

Alternatively it is possible that a direct genetic or metabolic effect on neural organization may not be involved or may be only partly responsible for higher IQ in this sample of patients. Because of their precocious physical development many of these patients tend to advance themselves socially, by mixing with older children as playmates. Some are allowed to advance to grades higher than dictated by chronological age as part of a program to assist them to a better social adjustment. The experience gained from this social advancement may lead to an increased sophistication with verbal concepts and in abstract thinking. This hypothesis is in keeping with the finding that Verbal IQ is generally higher than Performance IQ in these patients. Additional evidence for the hypothesis that social exposure is a relevant factor comes from the fact that the earliest developers, tested before age five, did not exhibit an elevated mean IQ. Still further, the highest of the subtests in the Performance section is Picture Arrangement, which presumably calls for some abstraction in concepts and some experience with everyday social situations. With the exception of this subtest, no subtest mean in the Performance section is higher than the lowest subtest in the Verbal section. The lowest of the Verbal subtests is Arithmetic. Some of the Arithmetic items are susceptible to the social influence of accelerated school experience, but at the time of the testing not all the children had been academically accelerated, as they might be later.

Results of the comparative study, relative to age of onset, mediate against the hypothesis of a simple and continuous relationship between social exposure and IQ elevation. Those children who matured early but were tested later would presumably have a longer time to develop verbal sophistication. The IQ median and the IQ distribution of the subgroup of such children, are, however, essentially the same as those of the other two subgroups. Both the comparative and longitudinal studies show that the developmental schedule for mental capacity in idiopathic sexual precocity dictates an early elevation of Verbal IQ and confers an advantage not given up in later years.
All in all, one may conjecture that idiopathic sexual precocity confers on a child a possible advantage in social exposure and participation with older agemates, which in turn confers an advantage in intellectual growth, particularly in the growth of verbal intelligence. This advantage shows up in a Verbal IQ superior to Performance IQ; a superiority which, once established, is maintained into adulthood. It is not like the temporary advantage of statural superiority that is terminated by premature epiphyseal closure. Whether or not the syndrome of idiopathic precocious puberty tends to induce high IQ, Verbal or Performance, is a question that cannot be answered from the present findings. Quite possibly it does. Yet, if such be the case for some children, it is not so for others. There are some on whom no intellectual advantage is conferred, for low IQ and mental retardation also concur with precocious puberty.

\section{References and Notes}

1. Hampson, J. G. and Money, J.: Idiopathic sexual precocity in the female: Report of three cases. Psychosom. Med. 17: 16-35 (1955).

2. Money, J.: Too early puberty. Sexology 28: 154 157 and 250-253 (1961).

3. Money, J.; Drash, P.W. and Lewis, V.: Dwarfism and hypopituitarism: statural retardation without mental retardation. Amer.J.ment. Defic. (in press).

4. Money, J. and Hampson, J. G.: Idiopathic sexual precocity in the male: Management, report of a case. Psychosom. Med. 17: 1-15 (1955).

5. Money, J. and Lewis, V.: IQ, genetics and accelerated growth: Adrenogenital syndrome. Bull. Johns Hopk. Hosp. 118: 365-373 (1966).

6. Money, J. and NeILL, J.: Developmental acceleration in children with precocious puberty: Somatic, intellectual, academic and social (in press).

7. Pollitt, E. and Money, J.: Studies in the psychology of dwarfism. 1. IQs and school achievement. J.Pediat. 64: 415-421 (1964).

8. WILKINS, L.: The diagnosis and treatment of endocrine disorders in childhood and adolescence; 3rd ed. (Thomas, Springfield, Ill. 1965).

9. Dr. Robert M.Blizzard and formerly the late Lawson Wilkins have been responsible for the pediatric endocrine care of patients herein reported.

10. Supported by Research Grant HD-00325, Research Career Development Award 5K3-HD-18635 and Medical Student Training Grant 2T2-MH5913, USPHS. 